\title{
Complementarity and Leverage as Drivers of the Stock Market Reaction to Global Alliance Formation
}

\author{
Marta Vidal Suarez and Esteban García-Canal
}

Companies are increasingly using global alliances to accelerate their international expansion. This paper identifies the critical factors that influence how the stock market will react to news of this type of alliance. We argue that abnormal returns on such news depend on the degree to which partners fill gaps in their international networks. We also argue that these alliances should be designed to take advantage of these complementarities in a well-defined geographical area. An empirical analysis of the stock market reaction to 72 global alliances by listed Spanish companies confirmed the importance of complementarity and leverage in explaining abnormal returns, and the irrelevance of the region of origin of the partner.

(c) 2003 Elsevier Ltd. All rights reserved.

\section{Introduction}

In 1987 Banco Santander, (now Santander Central Hispano Bank) realised that to meet the challenges of the European single market it needed a European dimension. At that time it was a medium-sized domestic bank ranking sixth in its home market but the advent of the European single market would force banks to cover a wider arena. However, for Banco Santander (BS), this was far from easy. Neither foreign acquisitions nor greenfield investments were a viable option due to financial constraints. The bank's approach therefore was to establish cross-border alliances, though not traditional ones. The bank's strategy pursued a new kind of agreement: a global alliance. For the purposes of this paper, global alliances are defined as multicountry agreements through which companies from different countries plan co-ordinated actions in several markets. Traditional international alliances (i.e. joint ventures with local partners) are aimed at one single country: that of the local partner. The Royal Bank of Scotland (RBoS), a bank not previously linked to BS, was chosen as a partner due to its similar size. The alliance comprised a framework agreement 
specifying several activities to be developed, and an equity exchange. BS bought 9.9 per cent of RBoS, which in turn acquired 4.9 per cent of BS, each firm becoming its ally's main stockholder. In the framework agreement, both partners specified three areas of co-operation: a joint investment policy in Europe; the interchange of networks of branches between Spain and the UK; and the development of a technological platform for international capital transfers. The alliance also entailed a commitment to leverage their synergies, as the scope of the alliance comprised the whole European Union. BS now had a new ally with whom it could compete in Europe. The establishment of this alliance created wealth for BS's shareholders and the stock market reacted positively to the announcement. ${ }^{1}$ In particular, the shareholders of the Spanish bank obtained an abnormal return of 2 per cent the day the deal was announced. ${ }^{\mathrm{a}}$

Considering this evidence, can we say that all global alliances increase shareholders' wealth in the same way? Not many studies deal with this issue. However, if we look at the more general literature dealing with stock market reaction to alliances, we would have to reply that they do not. One of the few clear implications of this literature (summarised in Exhibit 1) is that the stock market does not always react positively to the announcement of a strategic alliance. Even a global alliance does not always have positive consequences for a company-it has to meet certain requirements. In the case of the $\mathrm{BS} / \mathrm{RBoS}$ alliance, two specific features may be highlighted: first, the Spanish bank neither had previous experience in the UK market nor had it subsidiaries elsewhere in the EU. RBoS added specific know-how (which the Spanish bank lacked) in one of the most developed financial markets in the EU. Second, the alliance not only focused its scope on the UK

\section{Exhibit 1.}

\section{Do alliances increase shareholders' wealth? Why?}

Most studies analysing the stock market reaction to alliance formation—but not all—found a positive abnormal return, though no larger than 1 per cent. ${ }^{19}$ Results are even less conclusive when trying to analyse the factors that determine abnormal returns. The clearest result regarding alliance attributes is the importance of a technological component. Companies participating in technological alliances may benefit from these throughout more stages of the value chain and of the life cycle of the product than companies that form marketing alliances. Results concerning other factors related to the companies' characteristics (for instance, Tobin's q) or to alliance features, such as previous relationships between partners, are less conclusive.

As alliances are one of the options for expanding company boundaries, attributes related to internationalisation and diversification have been the focus of many empirical studies. Most of these have analysed traditional international joint ventures. For this reason, the main factors related to the internationalisation of the company analysed in this literature are the cultural distance between the partners and the economic status of the partner's country. Results are mixed for both of these factors. As regards diversification, we may identify two groups of studies. On the one hand, previous research has analysed alliances between competitors. There is some evidence that such alliances generate positive abnormal returns. These results could be explained by considering the fact that the chances of the parents' resources being fully exploited increase with competition between partners. However, not all the studies supported this hypothesis. On the other hand, previous literature has considered the relatedness between alliance activities and parent activities, and results show that this relatedness increases abnormal returns.

In view of these results, it is clear that more empirical studies are needed to learn more about the real determinants of abnormal returns. One impediment to find conclusive results might be that the empirical studies conducted have used samples which contained different types of alliances and have not always included the relevant control variables.

\footnotetext{
a See Appendix A for an explanation of how an abnormal return is calculated.
} 
and Spain, but on the entire EU. The benefits of the alliance were leveraged to the relevant domain. Thus, complementarity and leverage are at the core of value creation in the BS/RBoS case. Although some studies in alliance management have highlighted the relevance of these two attributes in international alliances, the impact of global alliance formation, and specifically, complementarity and leverage, on abnormal returns has not yet been documented.

The aim of this paper is to test how far these two attributes, complementarity and leverage, determine the stock market reaction to global alliance formation. Using event study techniques, we estimated the stock market response to the formation of global alliances created by listed Spanish companies between 1987 and 1997. The change from economic isolation to integration in the EU forced many Spanish companies to react quickly via global alliances. Our sample covers the period following the entry of Spain into the EU and hence includes the main global alliances formed by listed Spanish companies. We propose that the key driver to the increase of shareholders' wealth in global alliances is the association between companies with complementary resources that are also properly leveraged in the alliance. Our analysis fills a gap in the literature on the stock market response to alliances and is also of interest for managers trying to form global alliances.

\section{Theoretical framework: complementarity and leverage in global alliances}

Contemporary approaches to strategy are based on company heterogeneity. Not all companies are equal: they differ in their competences (their resource endowments as well as the way in which they assemble and manage them). This heterogeneity explains performance differences. However, the relationship between resources, competitive advantage and value creation of companies is complex. The custody of valuable resources is not the sole thing that is important: the key to outperforming competitors is not only to have more resources, but to leverage them, i.e. to get the most from available resources. ${ }^{2}$ At the same time, resource building and leverage is a dynamic process as, in order to keep creating wealth for their shareholders, companies need to be continually upgrading and leveraging their resources. ${ }^{3}$ In this section, we discuss how strategic alliances and, in particular, global alliances can help companies to manage their resources. After analysing how alliances can improve the competitive advantage of the company, we highlight the importance of geographical complementarity and alliance scope as determinants of the stock market reaction to global alliances.

The key to outperforming competitors is not only to have more resources, but to get the most from them.

Strategic alliances can improve the competitive position of a company in several ways. First, by allying with a similar organisation, a company may be turning a potential rival into a close collaborator. By doing so, companies start to compete as a block against other companies. Second, alliances can create unique combinations of resources that in turn create new market opportunities. These resource combinations are a source of competitive advantage for the partners, as they cannot be easily imitated by rivals. Third, an alliance can improve the competitive position of a company when the intangible assets of the partner are internalised through learning. These are the three main sources of value creation in strategic alliances highlighted by Doz and Hamel: co-option, co-specialisation and learning. ${ }^{4}$ In all three cases, a positive reaction of the stock market is to be expected, as the company is better off with respect to its competitors.

Although it is clear how an alliance can create value, the specific attributes of strategic alliances that increase shareholders' wealth are not so clear, as can be seen in Exhibit 1 . The advantages of strategic alliances to speeding up a company's international expansion are well known. ${ }^{5}$ Via global alliances, companies can access new customers and new technologies. Traditional local alliances do not have the same potential for creating such an advantage and are easily replicated by competitors. Global alliances, however, are more difficult to replicate. The number of potential partners 
with relevant resources and the willingness to enter into a multicountry agreement is lower than that of potential local allies. It is not easy to find a partner for a multicountry alliance, as the number of companies that enter this type of agreement is smaller than the number of companies that also enter local alliances. ${ }^{6}$ Companies entering global alliances can thus profit more from the advantages coming from co-option, co-specialisation and learning than those entering local alliances. For instance, in the case of the BS/RBoS alliance, both partners learned from each other how to improve their operating procedures. They also combined their resources, such as distribution networks, to create higher order resources. Finally, they had the goal of acting as a single unit within the EU, instead of competing against each other. It would appear then that global alliances can increase shareholders' wealth, but what is the best configuration for such alliances?

In order to attain the competitive advantages of global alliances, the partners' resources need to be complementary. If the partners' resources are redundant, alliances may fail to achieve their goals. The aim of a global alliance is to fill internal gaps to improve the international competitiveness of the participating companies. Thus, the key point in these alliances is the increase of the international scope of each company, which needs to be complementary if this goal is to be achieved. It does not matter where the partner comes from as long as the company has no presence in its partner's geographical domain. Complementarity does not mean the partners should belong to different industries. As Dussauge and Garrette point out, 'the main benefits of combining complementary skills appear in fact to accrue within the boundaries of existing industries. ${ }^{7}$ This is so because there are more opportunities to identify joint projects and to develop the relationship in the long term. Within this context, a complementary international scope means not only greater opportunities to complete an international network and to generate learning opportunities, but also more chances to develop the relationship. If the overlap in the partners' international presence is high, conflicts of interests could arise, thus hindering the development of trust. In fact, the benefits of global alliances arise in the long term as the alliance evolves into what Doz calls learning cycles, a situation in which partners develop their relationship with sequential and irreversible commitments. ${ }^{8}$ In the case of the BS/RBoS alliance, both companies had alternative geographical scope and knowledge. These features allowed them more opportunities for learning and co-specialisation, and also helped them to co-ordinate their international activities so as to act as a single unit within the EU. For instance, by connecting their information systems, they created the IBOS network (Interbank On-Line Systems), which facilitates cross-border transfers of capital.

Resource combinations assembled in strategic alliances also need to be leveraged. Leveraging resources could be defined as the art of doing more with less. ${ }^{9}$ For this reason, alliances are a good platform for leveraging resources. Once a higher-order combination of resources from different companies has been established, the key to maximising their potential is to leverage them. In the case of global alliances, the key to this lies in its breadth of geographical scope. These alliances are aimed at speeding up companies' international expansion and preparing for a global market, so the degree of international co-ordination of activities is critical. The increased scope of the partnership leads to greater opportunities to exploit economies of scale but it also implies growing commitments to the co-operative relationship. Furthermore, learning opportunities also increase with the scope of the global alliance. Thus, we could expect increases in the abnormal returns related to the formation of global alliances as the partners increase their international scope, as this allows them to exploit their resources to their full potential. In the case of the RBoS, both banks leveraged the alliance to the EU arena, where more opportunities for co-specialisation and co-opting arose. The IBOS network is an example of leverage: once the platform had been established, the network was opened to other European banks, and later even to non-European banks.

To sum up, global alliances increase shareholders' wealth when the company can take advantage of resource combinations. Contrary to the assumption of most of the previous research into the stock market reaction to international joint ventures, the drivers of abnormal returns are not to be found in the characteristics of the partners' country or region of origin, but in the degree to which the resources brought to the alliance are complementary and in the degree to which these resources are leveraged. 


\section{Empirical study}

\section{Methodology and data}

In order to test the impact of complementarity and leverage on the stock market response to global alliances, we constructed a database of global alliances by Spanish companies traded on the Madrid Stock Exchange. We considered as 'global' those international strategic alliances carrying out activities in more than one country. The final sample used in the study was composed of 72 global alliances created by 23 Spanish companies. (The process of construction of the database is detailed in Appendix A.) Some Spanish national champions, such as Telefonica or Endesa, were very active in global alliances. Generally, the companies in the sample were among the most important in Spain, and all were concerned with the challenges posed by the European single market, globalisation and deregulation. These forces were a special threat to these companies because of the isolation of the Spanish economy until 1986. This fact makes our data especially interesting within the sphere of this paper, as the companies in our sample were interested in accelerating their international scope. Table 1 includes a description of the main characteristics of these alliances with respect to time and industry distribution, number and nationality of partners, and geographic region of the alliance.

As our paper is focused around the stock market reaction to global alliance formation, we first calculated the abnormal return observed in the share price of the Spanish partner of each alliance included in our sample (Table 2). ${ }^{10}$ The specific procedure for doing so is also detailed in Appendix A. In particular, we observed an abnormal return of 0.19 per cent the day of announcement (day 0 ). We observed the highest reaction on this day, which was also the day on which the greatest number of companies obtained positive results. Taking into account the market value of each company (inflation adjusted to 1997 values), the wealth effects of these alliances ranged from $€$ 160 million gains to $€ 75$ million losses.

Not all the global alliances generated positive reactions: more than one third of the alliances in the sample prompted lower share prices on the day of the announcement. In order to discover the attributes that affected abnormal returns and above all to test the impact of complementarity and leverage, we estimated several multiple regression (ordinary least squares) models. The abnormal returns on the day of the announcement were used as the dependent variable. The independent and control variables used in these models are listed below.

We proxied the complementarity of partners' resources by using two variables: the first one (COMPETITORS) is a dummy variable, valued 1 when the partners are direct competitors, and 0 otherwise. In accordance with previous research, we consider that partners are direct competitors when they have the same three-digit SIC code. ${ }^{11}$ This information was obtained from the DUNS 50000 directory.

A second variable measuring complementarity is labelled LACK OF FDI. It focuses on the geographical scope of the partners. This is also a dummy variable, valued 1 when the Spanish company does not have a foreign subsidiary already in the area the partners come from, and 0 otherwise. In the case of the Spanish company already possessing an established subsidiary in the partner's zone of influence, the geographical complementary would be lower, as the distribution networks would be more redundant. ${ }^{12}$

Leverage was proxied by analysing the geographical scope of the alliance. We divided our sample of global alliances into three categories: (a) alliances with activities in only two countries; (b) alliances with activities in one region; and (c) alliances with an undefined scope.

None of the alliances in our sample claimed to have a worldwide scope. We expected alliances with activities in one region to be the best scenario for leveraging the synergies between partners. In our model, we included the variables WIDESCOPE and UNDEFINEDSCOPE, which take the value 1 when the alliance respectively has a geographical scope of one region or is undefined, and 0 otherwise. Thus, global alliances formed to carry out activities in only two countries act as a reference for the WIDESCOPE and UNDEFINEDSCOPE variables.

Some other variables were also introduced in our estimates in order to control factors that have 
Panel A: Global alliance frequency distribution by industry and year

\begin{tabular}{|c|c|c|c|c|c|c|}
\hline & \multirow[t]{2}{*}{$\begin{array}{l}\text { Construction } \\
\text { (SIC 15-17) }\end{array}$} & \multirow[t]{2}{*}{$\begin{array}{l}\text { Manufacturing } \\
\text { (SIC 20-39) }\end{array}$} & \multicolumn{2}{|c|}{$\begin{array}{l}\text { Transportation and utilities } \\
\text { (SIC 40-49) }\end{array}$} & \multirow{2}{*}{$\begin{array}{l}\text { Finance and } \\
\text { insurance } \\
\text { (SIC 60-67) }\end{array}$} & \multirow[t]{2}{*}{ Total } \\
\hline & & & SIC 48 & SIC 49 & & \\
\hline 1987 & & & & & 3 & 3 \\
\hline 1988 & & & 1 & 1 & 3 & 5 \\
\hline 1989 & 1 & 2 & & & 5 & 8 \\
\hline 1990 & 1 & 1 & 1 & & 8 & 11 \\
\hline 1991 & & & & 2 & 5 & 7 \\
\hline 1992 & & & 4 & 2 & 2 & 8 \\
\hline 1993 & & & 1 & 1 & 1 & 3 \\
\hline 1994 & 1 & 3 & 1 & 1 & 2 & 8 \\
\hline 1995 & 1 & & 1 & & 2 & 4 \\
\hline 1996 & & & 1 & & 3 & 4 \\
\hline 1997 & & 1 & 4 & 3 & 3 & 11 \\
\hline Total & 4 & 7 & 14 & 10 & 37 & 72 \\
\hline Per cent of total & 5.6 & 9.7 & 19.4 & 13.9 & 51.4 & \\
\hline
\end{tabular}

Panel B: Number and nationality of partners

\begin{tabular}{lllll}
\hline & $\begin{array}{l}\text { Two } \\
\text { partners }\end{array}$ & $\begin{array}{l}\text { Three } \\
\text { partners }\end{array}$ & $\begin{array}{l}\text { More than } \\
\text { three partners }\end{array}$ & Total \\
\hline UE & 41 & 1 & 5 & 47 \\
OECD & 12 & 2 & & 14 \\
Non-OECD & 9 & & 2 & 11 \\
Total & 62 & 3 & 7 & 72 \\
Per cent of total & 86.1 & 4.2 & 9.7 & \\
\hline
\end{tabular}

Panel C: Geographic region of the alliance

\begin{tabular}{lcll}
\hline & Number & Percentage \\
\hline Two countries & & 28 & 38.9 \\
One region & & 28 & 38.9 \\
UE & 18 & & \\
OECD & 1 & & \\
Non-OECD & 9 & 16 & 22.2 \\
Undefined scope & &
\end{tabular}

been found to be relevant in previous research, such as the region of origin of the partner, cultural distance, Tobin's q, the number of partners, and prior relationship between partners. These control variables are the following:

1 We first include some dummy variables relating to the geographical area where the partner comes from. Specifically, three areas were considered: the EU, the remaining OECD countries, and non-OECD countries. We introduced two of these categories in the estimates in our model, namely the variables EUROPEAN UNION and NON-OECD. These two variables are valued 1 
Table 2. Average abnormal returns for the sample of 72 global alliances during the period 1987-1997

\begin{tabular}{clll}
\hline $\begin{array}{c}\text { Day relative to } \\
\text { announcement }\end{array}$ & Average abnormal return (\%) & Z-Statistics & $\begin{array}{l}\text { Proportion of positive } \\
\text { abnormal returns (\%) }\end{array}$ \\
\hline-2 & 0.17 & 0.95 & 47.2 \\
-1 & 0.18 & 0.94 & 51.4 \\
0 & 0.19 & $1.99 * *$ & 62.5 \\
1 & 0.09 & 0.44 & 51.4 \\
2 & 0.07 & 0.36 & 54.1 \\
\hline
\end{tabular}

$* * p<0.05$.

Table 3. Independent and control variables

Variable name Description

Independent variables: Complementarity

Competitors A dummy variable, valued 1 when the partners are direct competitors and 0 otherwise

Lack of foreign direct investment A dummy variable, valued 1 when the Spanish company does not already have any subsidiary set up in the area where partners come from and 0 otherwise

Independent variables: Leverage Widescope

A dummy variable, valued 1 for global alliances in which partners plan to co-ordinate activities in more than two countries, which are well defined when the alliance is formed, and 0 otherwise

Undefinedscope A dummy variable, valued 1 when the geographical scope of the alliance is not defined at the time at which the alliance is formed, and 0 otherwise

Control variables

European Union countries

Non-OECD countries

Cultural distance

Tobin's q

Number of partners

Previous relationship

Year

Energy

Construction

Telecom

Financial

Manufacturing
A dummy variable, valued 1 when all partners come from the European Union, and 0 otherwise

A dummy variable, valued 1 when at least one of the partners comes from a country not belonging to the OECD, and 0 otherwise

Cultural distance between partners, measured following Kogut and Singh's measures, based on Hofstede's indexes

Tobin's q ratio of the Spanish company on the 31 December of the year prior to alliance formation

Number of partners in the alliance

A dummy variable, valued 1 when the partners had already collaborated previously, and 0 otherwise

The year the alliance was created

A dummy variable, valued 1 in those alliances carried out by energy companies

A dummy variable, valued 1 in those alliances carried out by construction companies

A dummy variable, valued 1 in those alliances carried out by telecommunication companies

A dummy variable, valued 1 in those alliances carried out by financial service companies

A dummy variable, valued 1 in those alliances carried out by manufacturing companies 
when all partners come from the EU or when at least one of the partners comes from a country not belonging to the OECD respectively, and 0 otherwise. Alliances formed by firms from OECD countries not integrated in the EU act as reference for these two variables.

2 CULTURAL DISTANCE: this variable measures the cultural distance between the countries of the partners in the alliance. We utilised the Kogut and Singh index, using updated measurements of Hofstede as input. ${ }^{13}$

3 TOBINQ is the q ratio of the Spanish company on 31 December of the year before alliance formation. ${ }^{14}$

4 NUMBER OF PARTNERS: this variable measures the number of partners in the alliance.

5 PREVIOUS RELATIONSHIPS: a dummy variable, valued 1 when partners had previously collaborated, and 0 otherwise. We considered the partners to have maintained an active collaboration when they had jointly participated in some consortium, local alliance or marketing or technological agreement. We searched in the PRENSA BARATZ (see Appendix A) database to find this information.

6 We also used other controls in our estimates regarding the year in which the alliance was created and the industry of the alliance. These variables are described in Table 3, which includes all the independent and control variables.

\section{Findings}

The results of our estimates are given in Table 4. The value of the coefficients of the independent variables, their standard error and an indication of their significance level are given. The explanatory power of the model (measured via the adjusted R-squared coefficient) is statistically significant. Taken as a whole, our results confirm the main prediction of our theoretical model. Our estimates regarding complementarity and leverage not only have the expected sign but are also significant.

As regards the complementarity of resources, our results show the positive relationship between competition between partners and abnormal returns. Competing companies have more opportunities to identify activities that can be shared or co-ordinated through alliances. However, in order to generate positive abnormal returns, alliances also need to be formed by companies with complementary international networks because the prior presence of the company through subsidiaries in the same area where the partner comes from destroys value. In such a case, the resources pooled by the partners could be redundant, and so cannot help the firms to bridge gaps. Therefore the international co-ordination of the activities of parent companies without creating overlaps seems to be the key to the formation of a global alliance resulting in a positive abnormal return.

The international co-ordination of the activities of parent companies without creating overlaps seems to be the key to the formation of a global alliance resulting in a positive abnormal return

Our study also shows that, when the alliance has a wide-ranging and well-defined geographical scope (WIDESCOPE), abnormal returns are higher than when it involves activities in just two countries-normally those of the partners. The scope of the alliance acts as a multiplicative factor in leveraging valuable resources from partners. A wide regional scope leverages the synergies between the partners, as the WIDESCOPE variable suggests. Our results for the UNDEFINEDSCOPE are interesting on that score. These results shows that the market does not value global alliances in which partners do not propose a detailed plan of joint actions for specific areas more than it does a two-country agreement. In fact, the sign of the UNDEFINEDSCOPE coefficient 
Table 4. Multiple lineal regression model estimations ${ }^{1}$

\begin{tabular}{lc}
\hline Variables & Coefficients \\
\hline Constant & $-2.8151(1.124)$ \\
Independent variables: complementarity & $0.8591^{* *}(0.344)$ \\
Competitors & $0.5909^{* *}(0.270)$ \\
Lack of FDI & \\
Independent variables: leverage & $1.0217^{* * *}(0.367)$ \\
Widescope & $-0.0401(0.333)$ \\
Undefinedscope & \\
Control variables & $-0.2632(0.345)$ \\
European Union countries & $-0.1784(0.565)$ \\
Non-OECD countries & $-0.1270(0.155)$ \\
Cultural distance & $1.3629^{* *}(0.579)$ \\
Tobin's q & $-0.1144^{* * *}(0.035)$ \\
Number of partners & $-0.0569(0.232)$ \\
Previous relationship & $0.0471(0.036)$ \\
Year & $1.6343(0.950)$ \\
Construction & $0.4091(0.378)$ \\
Telecom & $0.6519(0.427)$ \\
Financial & $-1.8804(0.94)$ \\
Manufacturing & 0.21 \\
Adj-R & $2.22^{* *}$ \\
F &
\end{tabular}

$N=72$ (standard errors in brackets).

Dependent variable: abnormal returns (\%) on day 0 .

${ }^{*} p<0.1 ;{ }^{* *} p<0.05 ;{ }^{* * *} p<0.01$.

${ }^{1}$ Heteroskedasticity-robust coefficients.

is negative although non-significant. Investors seem to remain doubtful as to these agreements with undefined scope until the partners show their actions and commitment to the alliance.

As far as the control variables are concerned, the most interesting result is the lack of significance of those related to the country and region where the partner comes from. Neither the geographical area of the partner nor the cultural distance between their countries of origin has a significant influence on abnormal returns. The lack of significance of cultural distance might be explained by the fact that although cultural distance could be an obstacle in the functioning of the alliance, it also indicates potential complementarity. Our sample may not be large enough to analyse this variable perfectly. However, the results of the geographical variables also show that partners' origin is not an important factor in explaining abnormal returns, at least in global alliances. Therefore, investors do not base their expectations on the partner's country or region of origin per se, but rather on the possibilities of leveraging complementary resources in a relevant arena.

In addition to country-specific factors, previous research into alliance management has also emphasised several factors that facilitate or hinder the functioning of the alliance. Cultural distance is one, as well as the existence of prior relationships or the number of partners. Managers should analyse not only the impact of these factors on alliance management, but also how they affect complementarity and leverage. We have just mentioned the fact that cultural distance, rather than being an obstacle, could be an opportunity for complementing resources. The results for prior relationships also support our view regarding the importance of leveraging resources. Previous research has shown that prior relations between partners may reduce the costs of running future alliances. However, we did not find this factor to be influential. These results seem to suggest that investors tend to value leveraged alliances that can rapidly improve the positioning of the company 
in the global arena, rather than other less ambitious projects that are gradually implemented. Another interesting result relates to the number of partners. In theory, a greater number of partners should increase the amount of resources pooled in the alliance. However, our results show a negative relationship, in the sense that when this number grows, abnormal returns diminish. Nevertheless, this result is consistent with our framework. Leveraging partners' synergies is not an easy task in multiparty alliances because, as the number of partners increases, the number of activities that can be co-ordinated without conflicts of interest decreases. Our results also show that the higher the $\mathrm{q}$ ratio of the company, the higher the abnormal return of the alliance. This ratio tells us how much the value of the whole package of assets exceeds the sum of the value of each asset separately. In general, it may be said that companies with a high q have valuable intangible assets. ${ }^{15}$ Companies with valuable intangible assets seem to be in a better position to gain most from global alliances, as they can attract better partners and/or ask for better conditions in their deals.

\section{Discussion and managerial implications}

As mentioned in Exhibit 1, most previous research into the stock market reaction to international alliances deals with traditional joint ventures. Unsurprisingly, most of this research has focused on the characteristics related to the host country in order to identify when these alliances generate positive abnormal returns. Alliances are not always the most effective way to enter a country. Greenfield investments forming wholly-owned subsidiaries or acquisitions are in some cases better methods of entering a foreign market. ${ }^{16}$ For this reason, the critical role played by the country of origin of the partner to explain the abnormal returns generated by traditional international alliances (i.e. those aimed at entering into one single country) is hardly surprising. ${ }^{17}$ However, when we wish to gain insights regarding when, how and where to form global alliances, this literature is not much help. This is due to the fact that global alliances have a different motivation to traditional joint ventures. They have a more strategic impact on competitive advantage, as companies can speed up their international expansion very rapidly as well as turn potential rivals into strong allies. Thus, the benefits of these alliances are not only generated in one country. They improve the competitive position of the company in the global arena. In this sense, the main contribution of our research is in highlighting the fact that global alliances generate abnormal returns, no matter where the partner comes from, if this partner has a complementary geographical scope and the alliance is designed to take advantage of this complementarity in a wide-ranging and well-defined geographical area. Complementarity and leverage are thus the key drivers in explaining abnormal returns in global alliances. We highlight the main implications of our findings in the following paragraphs.

The ideal partner is one with interests in the same core business and

located in a region in which the focal company has no presence.

Resource complementarity is at the heart of alliance formation. For this reason, stating that a partner should be complementary in an alliance might seem straightforward. However, complementarity also introduces difficulties in the management of the alliance: different national and corporate cultures; different business environments; different strategies and goals. As a consequence, companies should carefully select the degree of complementarity that they need from the partner. Our results show that in the case of global alliances, the ideal partner is one with interests in the same core business and located in a region in which the focal company has no presence. A partner which overlaps geographically adds less value and increases the chances of conflicts of interests. The case of RBoS and BS is a good example of choosing a complementary partner. RBoS had a complementary scope; it also had valuable expertise in a more developed financial system than the Spanish one: and it was not interested in entering the Spanish market on its own. 
However, complementarity alone does not allow companies to take full advantage of the benefits of global alliances. If a global partner can help a company to increase its international scope substantially, the alliance should be designed in a way that assures that resource complementarities are leveraged to their full potential. However, sometimes companies do not design their alliances to exploit all their synergies. The reason for doing so is the lack of trust between the partners, which makes them reluctant to assume excessive risks. Our results show that being highly conservative in a global alliance can be harmful for the company. Global alliances are aimed at speeding up internationalisation: in this respect, a reduced scope of the alliance would mean that the company is wasting its time in a relationship that does not enable it to reposition rapidly in the global arena. Obviously we are not encouraging managers to enter into a global alliance with their eyes shut. We are simply highlighting the most important challenge of managing a global alliance: being able to exploit the full synergies of a relationship from day one. Although our data does not allow us to establish recommendations on how to manage such alliances, the BS/RBoS case is a good example of how to do this. The alliance was designed to carry out simultaneously three co-operative projects in the EU. So as to overcome the lack of trust, the partners dedicated a great deal of effort from the outset to understanding each other's goals and to managing the alliance in a way that was profitable for both. For example, ad-hoc working teams were created for startingup and monitoring projects in human resources or marketing. Each side recognised that its partner had interesting resources and knowledge and both tried to develop skills to acquire information about their partners, to make decision processes, information and control systems and company culture compatible. They also created an ad hoc committee composed of the CEOs and top executives of each bank in order to monitor the evolution of the alliance. ${ }^{18}$

To sum up, our framework suggests that the real drivers of the stock market reaction to global alliance formation are to be found in resource complementarity and leverage. This should be the only limitation a manager interested in forming global alliances ought to consider: looking for partners with complementary resources and defining the scope of the alliance in a wide-ranging and well-defined geographical area. Thus, global alliances are not a growth expansion suitable for specific geographical areas alone. Our results show that global alliances generate positive abnormal returns if the company has no subsidiaries in the partner's area, no matter where the partner comes from. Moreover, factors such as cultural distance or the lack of previous relationships are not impossible limitations to overcome as their effect can be neutralised. Lack of synergy, however, is an impossible limitation to overcome in an alliance.

Although we believe that our study provides useful insights for identifying the value-creation potential of a strategic alliance, some characteristics could limit the indiscriminate, widespread extrapolation of our conclusions. In the first place, we have focused on a specific type of alliance: the global alliance. We did this deliberately because of a lack of empirical studies analysing this type of alliance. When identifying the critical factors explaining abnormal returns, we analyse these within the specific context of global alliances. Consequently, although the core of our framework could be applied to different types of alliances, such as technological or diversification alliances, certain changes should be made in each case. Second, we focused on alliances in which there was at least one Spanish partner. Although the case of Spain is interesting due to the pressures on Spanish companies to rapid internationalise in the late-1980s, our sample only included global alliances in which there was at least one listed Spanish partner. Finally, we exclusively studied the reaction of the capital market to the Spanish partners, only obtaining certain relevant information for these, such as Tobin's q. As some of the partners of the Spanish companies were not themselves listed, we focused on the Spanish partner so as not to reduce the sample size.

Some of our results highlight certain issues that further research should address. First, future research should shed light on the applicability of our results to contexts other than global alliances by Spanish companies. Empirical studies dealing with companies from several countries and different types of international alliances might analyse in depth the influence of complementarity and leverage on abnormal returns from international alliance formation. Second, it would be interesting to compare the determinant factors of value creation in global alliances and cross-border mergers 
and acquisitions, as both of these are alternative means to speed up international expansion. Event studies conducted in samples containing both types of action could shed light on the problem of when to choose one instead of the other. Finally, an extremely interesting question to analyse is how to manage global alliances. As we argue above, the real challenge of these alliances is their effective management. More empirical studies dealing with this issue would be very helpful for both managers and academics.

\section{Acknowledgements}

Financial support from Spain's Ministerio de Ciencia y Tecnología (Project SEC2000-0587) is gratefully acknowledged.

\section{Appendix A}

\section{Database and method for estimating abnormal returns}

The announcements of global alliances were identified by searching in the PRENSA BARATZ database for alliances created by listed Spanish companies between 1987 and 1997. This database includes all the economic news published daily in all Spanish newspapers. Via PRENSA-BARATZ, we searched for news items that fulfil the following requirements:

1 at least one Spanish company listed on the Madrid Stock of Exchange participated in the alliance;

2 the news article clearly reported on the interest of the company in achieving an effective internationalisation (mere financial stakes or hostile takeovers were not included in the sample);

3 the announcement specified the geographical scope of the alliance, so that it was possible to differentiate global alliances from other collaboration agreements such as local alliances.

We initially identified 87 global alliances carried out by 30 Spanish companies listed on the Madrid Stock Exchange. However, this sample was refined in order to be able to calculate abnormal returns. In particular, we excluded all those announcements of global alliances that were accompanied by seasoned equity offerings or stock reductions, takeover attempts or the payment of dividends in the 10 days before or after the date of the announcement. These were eliminated due to the difficulty in identifying which part of the abnormal return is caused by the formation of the global alliance. Likewise, we eliminated all those announcements in which the shares of the company had begun to be traded on the stock market a short time before the announcement of the global alliance, as there was not sufficient information to estimate abnormal returns. The sample was thus reduced from 87 to 72 announcements of global alliances.

Event studies attempt to estimate to what extent a particular event influences the return on a share, i.e. to what extent the returns on a share differ from those expected if such an event had not taken place. With regard to this, the null hypothesis assumes the non-existence of abnormal returns. These abnormal returns are defined as the difference between the actual returns observed and those expected according to the model in a time window located around the announcement of a certain event. If the empirical evidence rejects this hypothesis, this would imply the existence of statistically significant abnormal returns. In order to calculate abnormal returns we specifically followed the procedure of Dodd and Warner. ${ }^{20}$

The estimate of the market model was carried out using data from an interval of 120 days, which started 130 days before the date of the announcement $(t=-130)$ and finished 11 days before this same date $(t=-11), t=0$ being the day when the news was published in one of the economic newspapers consulted. The exclusion of the ten days prior to the announcement from the estimate of the market model seeks to remove data that might be affected by the event. Its 
inclusion might lead to an underestimate of the abnormal returns as a result of the effect of the announcement being partially incorporated in the expected returns. These abnormal returns are calculated for each one of the days that make up the time window of the period under study. The abnormal returns accumulated are obtained for each share, aggregating the abnormal returns of the days on which the greatest reaction in the share price occurred. The reactions produced in the share price in the Spanish case led us to calculate the abnormal returns in different periods, all within the range $t=-2$ and $t=+2$, as this was the time period in which the major reactions were concentrated, although in many cases the major market response is concentrated on the day of the announcement. Brown and Warner's statistics were used to test the null hypothesis, namely, that the abnormal returns accumulated during the days around the event are equal to zero. ${ }^{21}$

\section{References}

1. The BS/RBoS is a well-documented example of a successful international alliance. See, for instance, J. Child and D. Faulkner, Strategies of Cooperation: Managing Alliances, Network, and Joint Ventures, Oxford University Press, NY (1998).

2. G. Hamel and C. K. Phahalad, Strategy as stretch and leverage, Harvard Business Review March-April, 75-84 (1993).

3. R. Sanchez, A. Heene and H. Thomas (eds), Dynamics of Competence-Based Competition: Theory and Practice in the New Strategic Management, Elsevier-Pergamon, London (1996).

4. Y. L. Doz and G. Hamel, Alliance Advantage in The Art of Creating Value through Partnering, Harvard Business School Press, Boston (1998).

5. M. E. Porter and M. Fuller, Coalitions and global strategy, in M. Porter (ed.) Competition in Global Industries, Harvard Business School Press, Boston 315-343 (1986). K. Ohmae, The global logic of strategic alliances, Harvard Business Review March-April, 143-154 (1989). D. Lei and J. W. Slocum Jr, Global strategic alliances: Payoffs and pitfalls, Organizational Dynamics 44-62 (1991).

6. E. García-Canal, C. López, J. Rialp and A. Valdés, Accelerating international expansion through global alliances: A typology of cooperative strategies, Journal of World Business 37, 91-107 (2002).

7. P. Dussauge and B. Garrette, Cooperative Strategy. Competing Successfully through Strategic Alliances in Wiley, NY (1999).

8. Y. L. Doz, The evolution of cooperation in strategic alliances: Initial conditions or learning processes? Strategic Management Journal 17, 55-83 (1996). See also R. M. Grant and C. Baden-Fuller, The Knowledge-based view of strategic alliance formation: Knowledge accessing versus organizational learning, in F. J. Contractor and P. Lorange (Eds.), Cooperative Strategies and Alliances, Pergamon, p. 419-436 (2002).

9. G. Hamel and C. K. Phahalad, Competing for the Future in Harvard Business School Press, Boston, Mass (1994).

10. A. McWilliams and D. Siegel, Event studies in management research: Theoretical and empirical issues, Academy of Management Journal 40, 626-657 (1997).

11. S. H. Park and D. Kim, Market valuation of joint ventures: Joint venture characteristics and wealth gains, Journal of Business Venturing 12, 83-108 (1997).

12. We build this variable based on Hitt et al., who argued that partner selection in international alliances should be driven by the aim of filling internal gaps. M. Hitt, T. Dacin, E. Levitas, J. Arregle and A. Borza, Partner selection in emerging and developed market contexts: Resource-based and organizational learning perspectives, Academy of Management Journal 43, 449-467 (2000).

13. B. Kogut and H. Singh, The effect of national culture on the choice of entry mode, Journal of International Business Studies 19, 411-432 (1988). G. Hofstede, Culture's Consequences: International Differences in Work-related Values, Sage Publications, Beverly Hills, 2nd ed. (2001). If there were more than two partners, we followed the procedure employed by K. Kim and J. Park, The determinants of value creation for partner firms in the global alliance context, Management International Review 42 (2002). Specifically, for each pair of partners we calculated the Kogut and Singh (op. cit.) index, and then we calculated the average between these indices.

14. Specifically, we followed the procedure of K. H. Chung and S. W. Pruitt, A simple approximation of Tobin's q, Financial Management, 23, 70-74 (1994).

15. R. Morck, A. Shleifer and R. W. Vishny, Management ownership and market valuation, Journal of Financial Economics 20, 293-315 (1988); R. Mork and B. Yeung, Why investors value multinationality, Journal of Business 64, 165-187 (1991). 
16. See, for instance, E. Anderson and H. Gatignon, Modes of foreign entry: A transaction cost analysis and propositions, Journal of International Business Studies 17(3), 1-23 (1986).

17. In an interesting paper also published in this issue, Sleuwaegen et al. found that the region of origin of the partner influenced abnormal returns, using a sample of international strategic alliances formed by Dutch firms. As their sample includes all types of international alliances this result does not contradict ours, because we are only analysing global (that is, multicountry) alliances. See L. Sleuwaegen, K. Schep, G. Den Hartog and H. Commandeur, Value creation and the alliance experiences of Dutch companies, Long Range Planning, this issue.

18. More information on how the BS/RBoS alliance was designed to overcome this problem can be found in E. García-Canal, C. López-Duarte, J. Rialp and A. Valdés, Time compression diseconomies in accelerated global alliances, Management Decision, 40(8), 745-754 (2002).

19. A good review of empirical studies of factors influencing the stock market reaction to international alliances formation can be found in S. Chen, W. Kim, C. Lee and G. Yeo, Investment opportunities, free cash flow and market reaction to international joint ventures, Journal of Banking and Finance 24, 1747-1765 (2000). See also H. Merchant and D. Schendel, How do international joint ventures create shareholder value? Strategic Management Journal 21, 723-737 (2000).

20. P. Dodd and B. Warner, On corporate governance: A study of proxy contests, Journal of Financial Economics 11, 408-438 (1983).

21. S. J. Brown and J. Warner, Using daily stock returns, Journal of Financial Economics 14, 3-31 (1985).

\section{Biographies}

Marta $\mathrm{M}^{\mathrm{a}}$ Vidal Suarez is Associate Professor of Management at the University of Oviedo, Spain. She received her Ph.D. in Business Administration from the University of Oviedo in 2000. Her research interests include global alliances and inter-partner relationships, corporate governance and organisational economics. Her research has been presented at the Academy of Management and Strategic Management Society Annual Meetings and published in Management Research and European Business Review, among other journals. E-mail: mmvidal@correo.uniovi.es

Esteban García-Canal is Associate Professor of Management at the University of Oviedo (Spain) and Associate Member of the Instituto Empresa y Humanismo at the University of Navarra, where he also previously taught. He received his Ph.D. in Business Administration from the University of Oviedo. His research interests are focused on the confluence between Organisational Economics, Corporate Strategy and International Business. His research has been published in Organization Studies, Journal of World Business, Journal of Institutional \& Theoretical Economics (JITE), Journal of Management \& Governance, Management International Review, Management Research and Thunderbird International Business Review, among other journals. Currently, he is a member of the Editorial Boards of the Journal of International Business Studies (JIBS) and Revista de Empresa. E-mail: egarcia@correo.uniovi.es 